\title{
Article \\ Photo-Sintered Silver Thin Films by a High-Power UV-LED Module for Flexible Electronic Applications
}

\author{
Minha Kim, Hongsub Jee and Jaehyeong Lee *D \\ Department of Electrical and Computer Engineering, Sungkyunkwan University, Suwon 16419, Korea; \\ pratice1dea@naver.com (M.K.); hsjee@skku.edu (H.J.) \\ * Correspondence: jaehyeong@skku.edu
}

Citation: Kim, M.; Jee, H.; Lee, J. Photo-Sintered Silver Thin Films by a High-Power UV-LED Module for Flexible Electronic Applications. Nanomaterials 2021, 11, 2840. https:/ / doi.org/10.3390/nano11112840

Academic Editor: Aurora Rizzo

Received: 31 August 2021

Accepted: 20 October 2021

Published: 25 October 2021

Publisher's Note: MDPI stays neutral with regard to jurisdictional claims in published maps and institutional affiliations.

Copyright: (c) 2021 by the authors. Licensee MDPI, Basel, Switzerland. This article is an open access article distributed under the terms and conditions of the Creative Commons Attribution (CC BY) license (https:// creativecommons.org/licenses/by/ $4.0 /)$.

\begin{abstract}
In recent printed electronics technology, a photo-sintering technique using intense pulsed light (IPL) source has attracted attention, instead of conventional a thermal sintering process with long time and high temperature. The key principle of the photo-sintering process is the selective heating of a thin film with large light absorption coefficients, while a transparent substrate does not heat by the IPL source. Most research on photo-sintering has used a xenon flash lamp as a light source. However, the xenon flash lamp requires instantaneous high power and is unsuitable for large area applications. In this work, we developed a new photo-sintering system using a high-power ultraviolet light emitting diode (UV-LED) module. A LED light source has many merits such as low power consumption and potential large-scale application. The silver nanoparticles ink was inkjet-printed on a polyethylene terephthalate (PET) and photo-sintered by the UV-LED module with the wavelength of 365 and $385 \mathrm{~nm}$. The electrical resistivity as low as $5.44 \times 10^{-6} \Omega \cdot \mathrm{cm}$ (just about three times compared to value of bulk silver) was achieved at optimized photo-sintering conditions (wavelength of $365 \mathrm{~nm}$ and light intensity of $300 \mathrm{~mW} / \mathrm{cm}^{2}$ ).
\end{abstract}

Keywords: silver thin film; photo-sintering; ultraviolet light emitting diode (UV-LED); low temperature process; flexible substrate

\section{Introduction}

For decades, printed electronics technology has been developed with materials like metal nanoparticles ink, non-contact technology like drop-on-demand inkjet technology for printing materials on any substrate, and post-treatment process in order to obtain good properties from materials [1-8]. In particular, a new frontier of printed electronics is to print flexible and stretchable electronic devices for wearable electronics [9-11]. These developments are expected to offer many advantages such as flexibility, low cost, and simple process compared with to existing processes in industry. Recently, thanks to the developments, printed electronics have applied to radio-frequency identification (RFID) tags, display, and various types of sensors [12,13].

Conductive inks based on highly concentrated metal nanoparticles have special physical properties different from the bulk metal. For example, the metal nanoparticles with high surface to mass ratio have high absorption and low melting point compared to the bulk metal. Generally, since the metal nanoparticles inks could be polarized by electromagnetic wave propagating along metal-solvent dielectric boundary, these particles have plasmon resonance peaks depending on particle size and shape, dielectric constant of external solvent and these particles, and substrate optical properties [14]. In particular, the metallic particles can be shown to have stronger absorption than the light incident at ultraviolet frequencies [15].

In general, traditional thermal processes are very difficult to apply to flexible polymer substrates since high temperature would destroy the substrate and inert gas for good electrical properties. Therefore, various techniques have been used to sinter silver nanoparticles, 
including chemical self-sintering [16,17], electrical [18-20], infrared [21-24], laser [25-27], microwave [28-30], plasma [31-34], and photo sintering methods [35-41]. Among these post-annealing processes, photo-sintering has been the center of attention as a new method process without significantly heating the substrate [42]. Recently, photo-sintering technology has been applied to a variety of nanoparticles [43,44] and nanowires [45-47] for low-temperature processing. The key principle is the selective heating of a thin film composed of metal nanoparticles with strong absorption property, which is an essential parameter needed to increase the energy transfer from light, while the temperature of transparent substrate does not rise up by an intense pulsed light (IPL) source. Photosintering has very strong merit in that the process is very easy and is carried out at room temperature under air atmosphere conditions [48]. Many researchers have used a xenon flash lamp with wide-range wavelengths for photo-sintering and investigated the effects of flashing frequency and light intensity on the properties of materials. However, IPL needs an instantaneous high power, which is one of the main reasons for very expensive system cost, and has the problem of uniform light intensity for large-area applications.

Therefore, in this work, we invented a new photo-sintering system using high-power ultraviolet light emitting diode (UV-LED) modules with different wavelengths for sintering silver nanoparticle thin film ink-jet printed on the PET substrate. When using highintensive LED, easily-controllable sintering time, needless high-voltage, more-efficient power consumption, and better durability, could be much friendlier to large-scale industry. Effects of photo-sintering parameters such as light intensity, irradiation duration, and wavelength of UV-LEDs on the electrical properties of Ag thin films were investigated.

\section{Experimental Details}

Silver nanoparticles ink was obtained commercially: an ethylene glycol-water based silver nanoparticles ink (JS-B25P, Novacentrix, Austin, TX, USA), with a particle size of $102.3 \mathrm{~nm}(93.5 \%), 14.53 \mathrm{~nm}(6.5 \%)$, and average particle size $71.9 \mathrm{~nm}$. The initial content of silver in the ink was $25 \%$. The silver ink viscosity of $4.60 \mathrm{cP}$ at $22.0^{\circ} \mathrm{C}$ and the surface tension of 31.2 dynes/cm were suitable for Epson Workforce 30 (Epson, Suwa, Japan), a high resolution and performance piezoelectric printer. The ink was printed on $\mathrm{Novel}^{\mathrm{TM}}$ (Novacentrix, Austin, TX, USA) PET substrate with the area of $1 \times 1 \mathrm{~cm}^{2}$. The photosintering of Ag thin films was performed by the UV-LED module. The module composing of $2 \times 20$ arrays was made of high-power UV-LEDs with two wavelengths of $365 \mathrm{~nm}$ (NC4U133A(T), Nichia, Anan, Japan) and 385 nm (NC4U134A(T), Nichia, Japan), as shown in Figures 1 and 2. The electric circuits consisting of 2-series by 20-parallels connection was suitable for DC power supply, PAX 35-20 (Kikusui, Yokohama, Japan) with voltage range 0 to $35 \mathrm{~V}$ and current range 0 to $20 \mathrm{~A}$. The light intensity of the module was controlled by adjusting the current of the DC power supply. The light intensity per unit area $\left(\mathrm{W} / \mathrm{cm}^{2}\right)$ corresponding to the current was confirmed by a UV radiation measurement (UIT-150, Ushio, Tokyo Japan) (Table 1). All photo-sintering processes were performed at $20^{\circ} \mathrm{C}$, in air atmosphere, and under $40 \%$ humidity conditions. Samples were placed in a position $1 \mathrm{~mm}$ away from the quartz plate, which was intended to protect the UV-LED module. In addition, the silver thin film was positioned upward since a solvent evaporated from the silver ink during sintering clings to the quartz plate. For comparison, a thermal sintering of silver film was performed in the vacuum dry oven.

The thermogravimetric curves of the silver ink were analyzed by a thermogravimetry differential thermal analyzer (TG-DTA, TG/DTA7300, SII Nanotechnology Inc., Tokyo, Japan) under nitrogen gas atmosphere. Optical spectra of the silver-ink was obtained with a UV-visible absorption spectrometer (UV-VIS, S-3100, Scinco, Seoul, Korea). The sheet resistance was measured by a four-point probing system (CRESBOX, Napson Corporation, Tokyo, Japan). The crystal structure analysis of the silver film deposited on the PET substrates was investigated by X-ray Diffractometer (XRD, DB Advance, Bruker, Billerica, MA, USA). The microstructures and the surface morphologies of the silver thin films were examined by field emission scanning electron microscopy (FE-SEM, JSM6700F, JEOL, 
Tokyo, Japan). The surface temperature of the silver film during photo-sintering was measured by four-input thermometer (TES-1384, TES, Taipei, Taiwan).

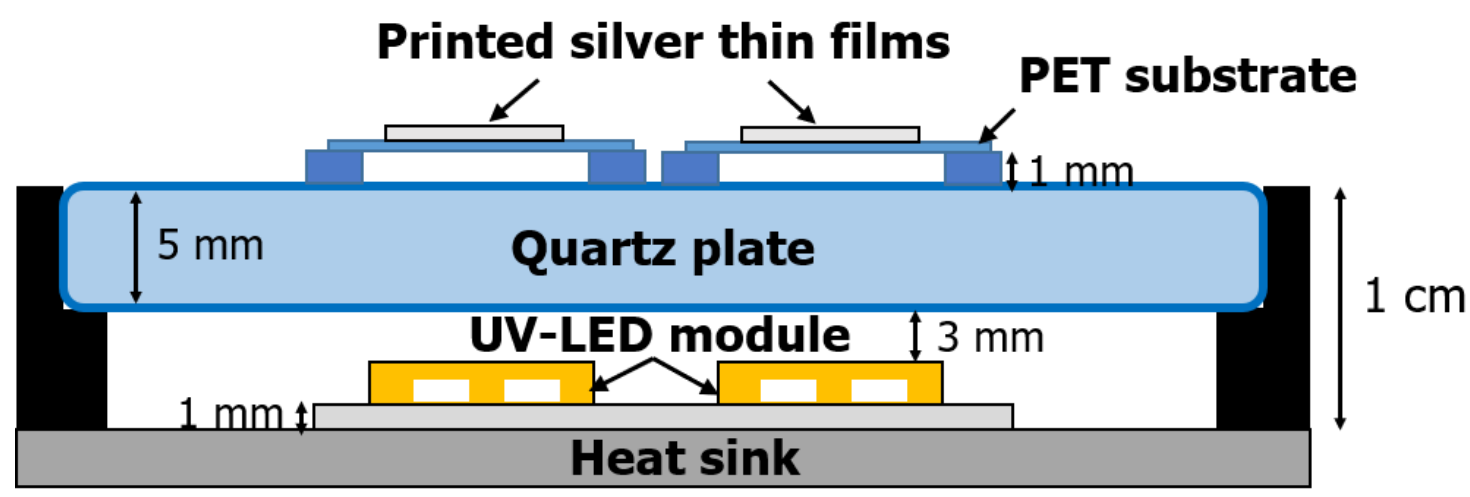

Figure 1. Schematic diagram of the high-power UV-LED module system.

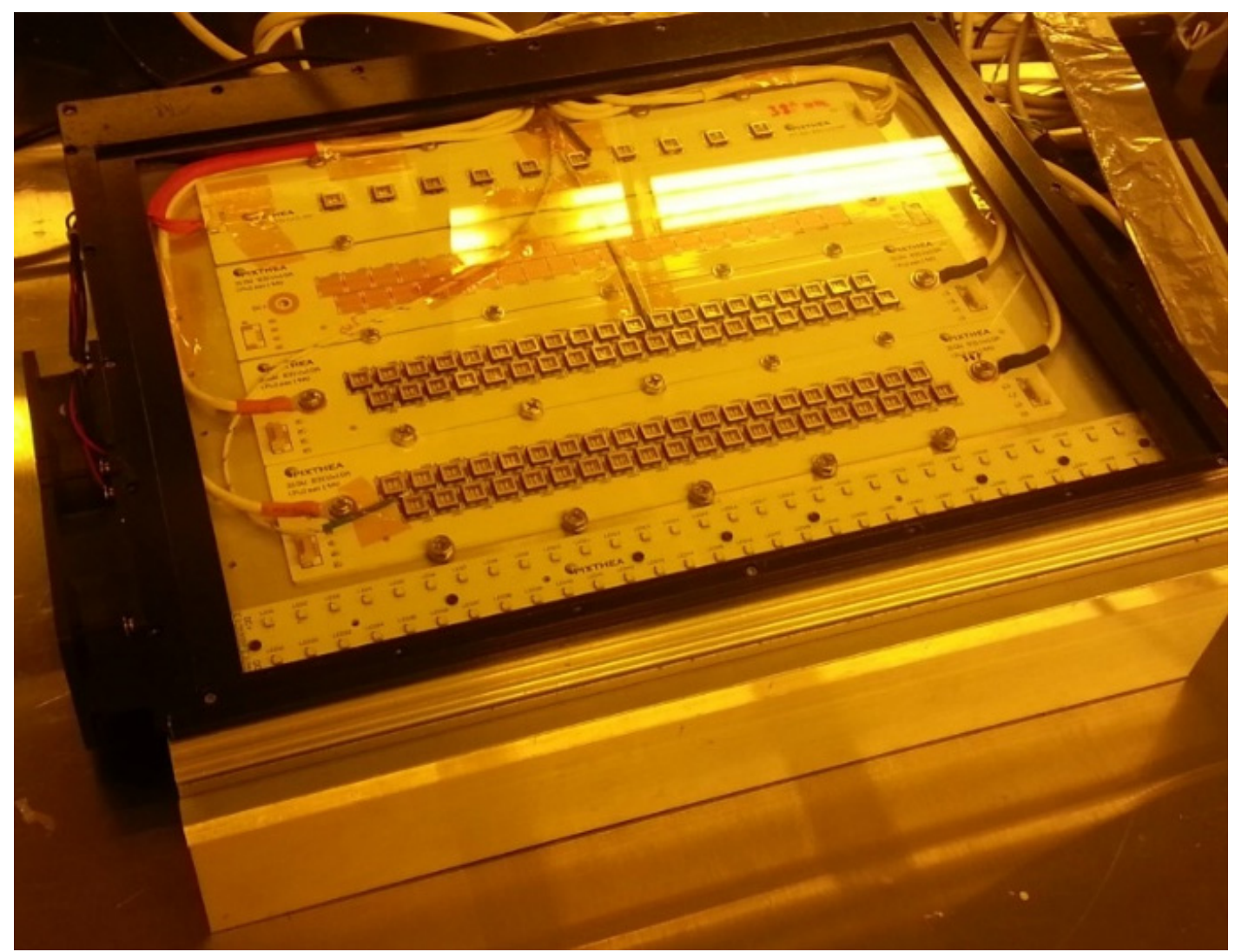

Figure 2. Prototype of the UV-LED module with a heat sink.

Table 1. Light intensities per unit area and surface temperature of UV-LEDs at some input currents.

\begin{tabular}{ccccc}
\hline $\begin{array}{c}\text { Wavelength } \\
(\mathbf{n m})\end{array}$ & Input Current (A) & $\begin{array}{c}\text { Input Current per } \\
\text { LED (mA) }\end{array}$ & $\begin{array}{c}\text { Saturation } \\
\text { Temperature }\left({ }^{\circ} \mathbf{C}\right)\end{array}$ & $\begin{array}{c}\text { Measured Light } \\
\text { Intensity }\left(\mathbf{m W} / \mathbf{c m}^{\mathbf{2}}\right)\end{array}$ \\
\hline 365 & 1.1 & 55 & 40 & 106.0 \\
365 & 1.7 & 85 & 48 & 171.1 \\
365 & 2.3 & 115 & 57 & 230.0 \\
365 & 3.1 & 155 & 69 & 301.0 \\
385 & 1 & 50 & 33 & 168.1 \\
385 & 1.3 & 65 & 35 & 226.8 \\
385 & 1.7 & 85 & 37 & 301.8 \\
\hline
\end{tabular}




\section{Results and Discussion}

Figure 3 shows the optical absorbance spectra of the silver nanoparticle ink and the PET substrate. The UV-visible spectrophotometer measures the optical absorbance. The absorption can be calculated from the following equation.

$$
A(\%)=\left(1-10^{-\alpha}\right) \times 100
$$

where $A$ is the absorption and $\alpha$ is the absorbance $[49,50]$. The silver ink exhibited very high absorption (near 100\%) at the wavelength of 365 and $385 \mathrm{~nm}$, while the PET substrate appeared with optical absorption over 50\%, as shown in Figure 4. The light absorption of the silver nanoparticles may be attributed to the localized surface plasmon resonance (LSPR), which is the resonant photon-induced coherent oscillation of charge at the metaldielectric interface when the photon frequency matches the natural frequency of the metal surface electrons oscillating against the restoring force of their positive nuclei [51].

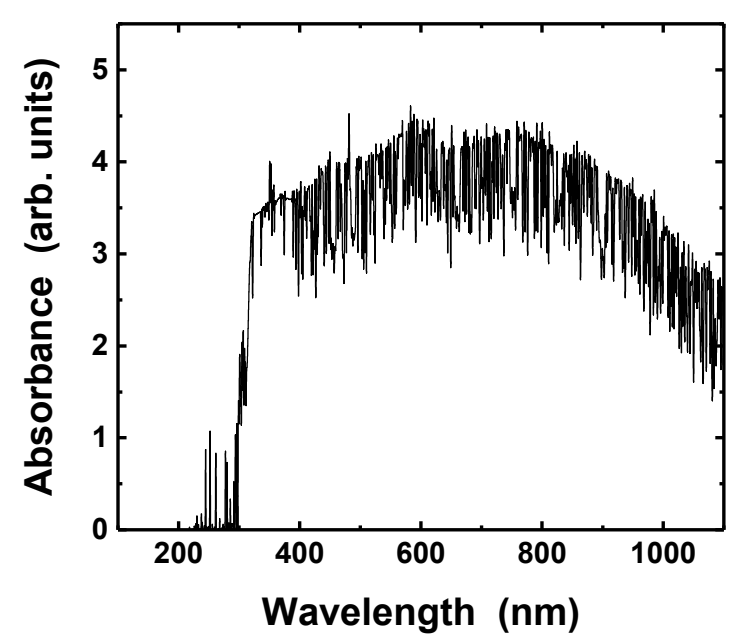

(a)

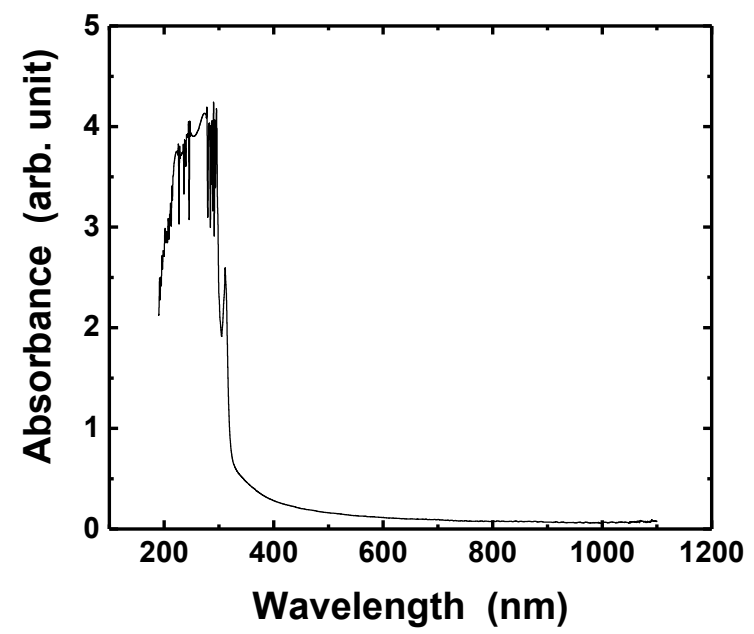

(b)

Figure 3. Absorbance spectra of the silver nanoparticle ink (a), PET substrate (b).

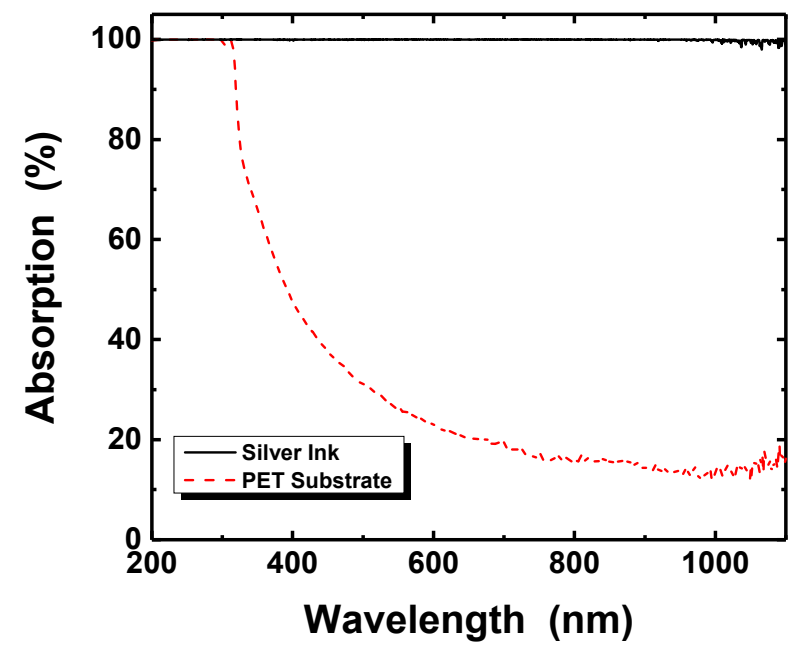

Figure 4. Optical absorption spectra of Ag nanoparticle ink and PET substrate.

Figure 5 displays the TG, DTA, and DTG curves of the silver ink in the temperature range from 25 to $500^{\circ} \mathrm{C}$. The heating rate was $10^{\circ} \mathrm{C} / \mathrm{min}$. DTA data indicate endothermic reactions at two specific temperatures $\left(74.1\right.$ and $\left.176.4^{\circ} \mathrm{C}\right)$ and exothermic reaction at one specific temperature $\left(405.4{ }^{\circ} \mathrm{C}\right)$, respectively. First endothermic reaction at $74.1^{\circ} \mathrm{C}$ with 
an initial weight loss of $45 \%$ may be the result of evaporation of a residual solvent, water. Second endothermic reaction at $176.4^{\circ} \mathrm{C}$ is closely related to a residual solvent, ethylene glycol with the boiling point of $197.3^{\circ} \mathrm{C}$. There is endothermic reaction until approximately $240{ }^{\circ} \mathrm{C}$, according to DTA results. Over this temperature, most of the solvent in the silver ink can be expected to disappear by heating. However, interestingly there is still a little weight loss from 240 to $405.4{ }^{\circ} \mathrm{C}$ (exothermic reaction temperature). It is postulated that residues from some surfactants in the ink are decomposed thermally. From DTG results, three main ingredients in the ink were confirmed. The two peaks at 72.1 and $160.6{ }^{\circ} \mathrm{C}$ correspond to water and ethylene glycol, respectively, and the weak peak at $400.2{ }^{\circ} \mathrm{C}$ might be associated with a little surfactant. In particular, at temperature near the boiling point of ethylene glycol, its dehydration, following Equation (2), could happen to reduce metal oxide nanoparticles [52].
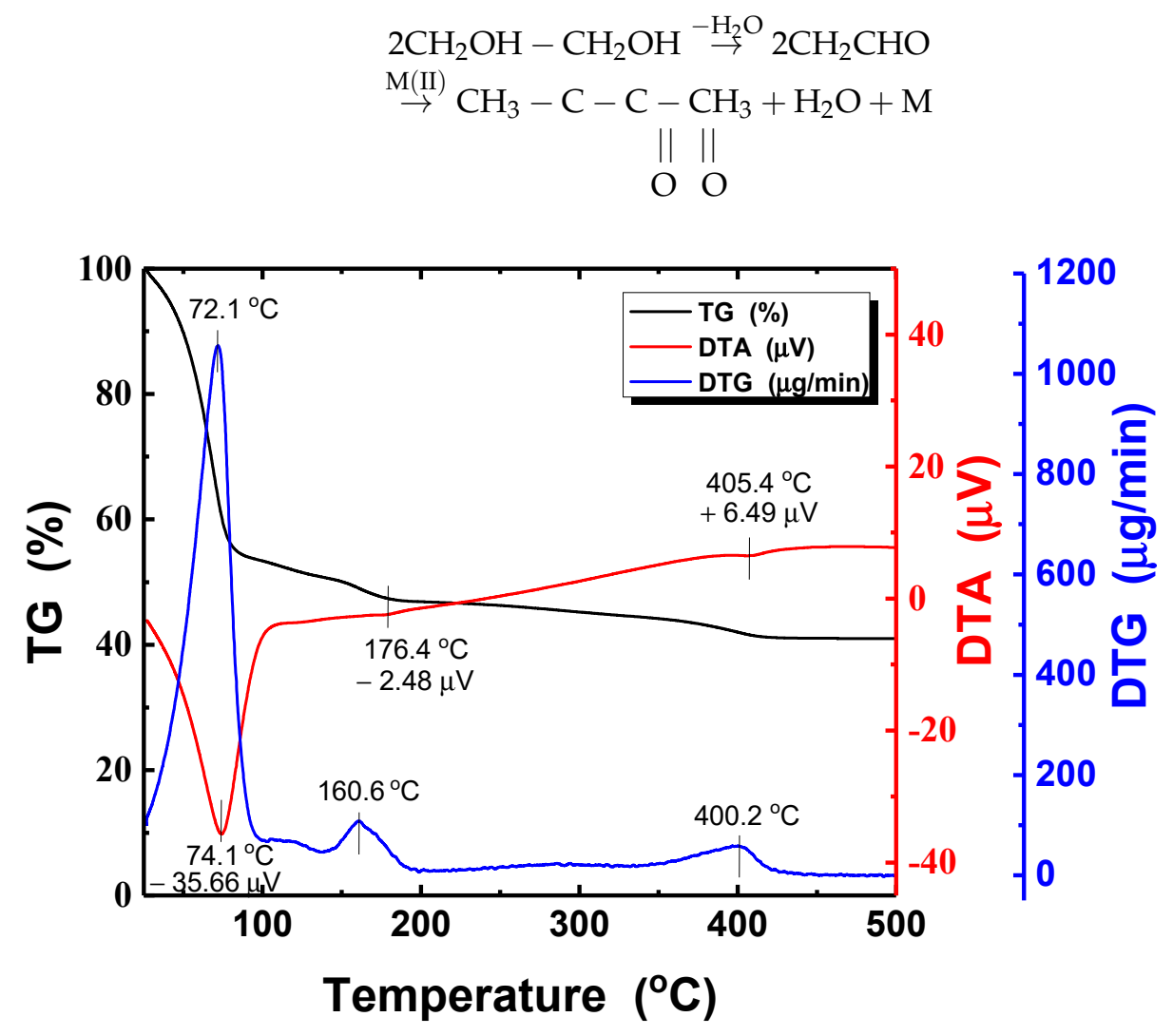

Figure 5. Thermogravimetric (TG), differential thermal analysis (DTA), and derivative thermogravimetric (DTG) of the silver nanoparticle ink.

For good electrical properties, all solvents in the silver thin film must be eliminated. Therefore, at least, over ethylene glycol's dehydration temperature $\left(160^{\circ} \mathrm{C}\right)$, post-annealing treatment should be carried out for crystallization.

From TG/DTA analysis, we knew at least the temperature of $160.6^{\circ} \mathrm{C}$ might be required for post-treatment of the silver ink. Figure 6 shows the sheet resistance of silver thin films annealed at different temperatures and for various durations in the vacuum. When the process temperature was over $180{ }^{\circ} \mathrm{C}$, PET substrate became bent and damaged. On the other hand, at the annealing temperature lower than $90^{\circ} \mathrm{C}$, the films exhibited very high sheet resistance (over $2 \mathrm{M} \Omega$ /sq.), although process time was several hours.

The change of the resistivity in the temperature range from 120 to $150{ }^{\circ} \mathrm{C}$ may be attributed to dehydration of ethylene glycol. Under $90^{\circ} \mathrm{C}$, only water in the silver film is evaporated simply without any chemical reaction. There was still ethylene glycol in the silver film, and also the temperature might have too little energy to crystallize silver nanoparticles. When the temperature increased to $120^{\circ} \mathrm{C}$, some chemical reactions like 
ethylene glycol's dehydration and evaporation could occur in the silver film. However, it does not seem enough to crystalize silver film as can be expected from high resistivity. As the temperature further increased to $150{ }^{\circ} \mathrm{C}$, the resistivity decreased significantly. Although the temperature was not over $160^{\circ} \mathrm{C}$ (ethylene glycol's dehydration temperature), the film could evaporate ethylene glycol for a long time, and there might be chemical reaction, which looks capable of crystalizing it. Ag thin film thermally treated at $150{ }^{\circ} \mathrm{C}$ for 50 min exhibited the resistivity of $2.06 \times 10^{-4} \Omega \cdot \mathrm{cm}$.

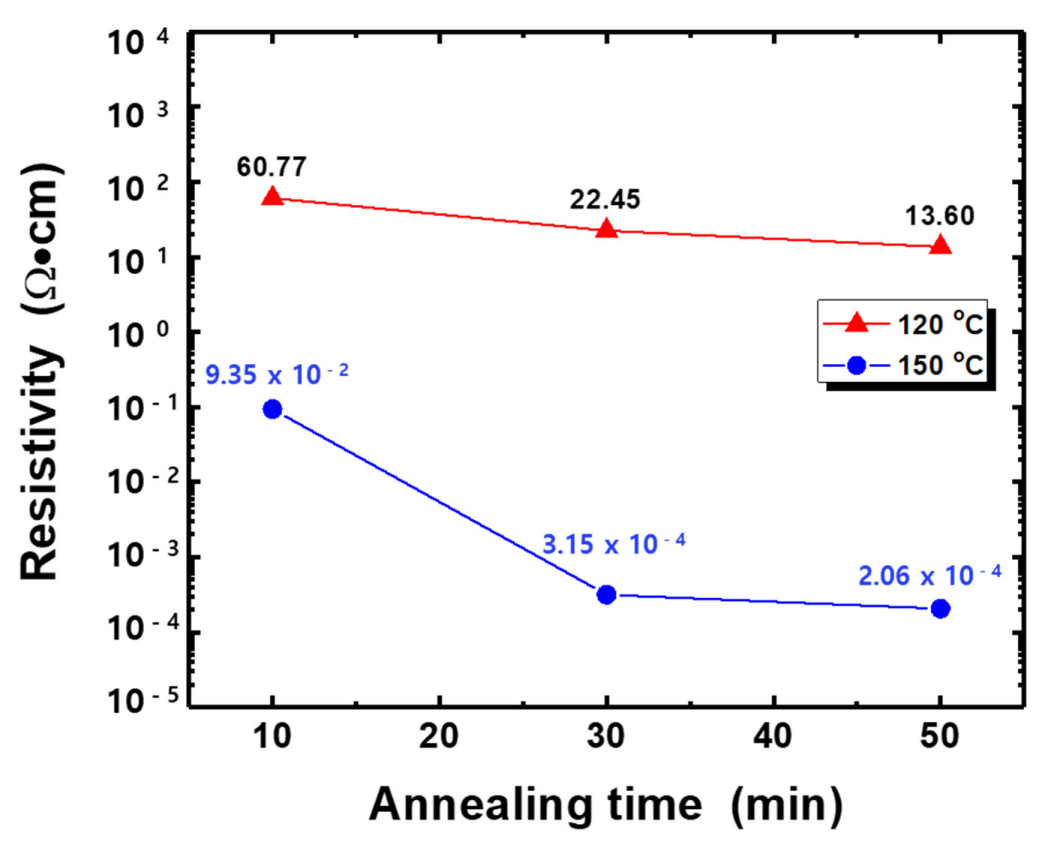

Figure 6. Electrical resistivity of silver thin films thermally treated at different temperatures and for various durations. The film thickness was about $700-800 \mathrm{~nm}$.

Figure 7 displays the surface morphologies of silver films thermally treated at different temperatures and various durations. There is little change of the surface structure when the film was thermally treated for a short duration (i.e., $10 \mathrm{~min}$ ), regardless of the temperature. However, some large size nanoparticles appeared on the film surface as the treatment duration became longer, especially $50 \mathrm{~min}$.

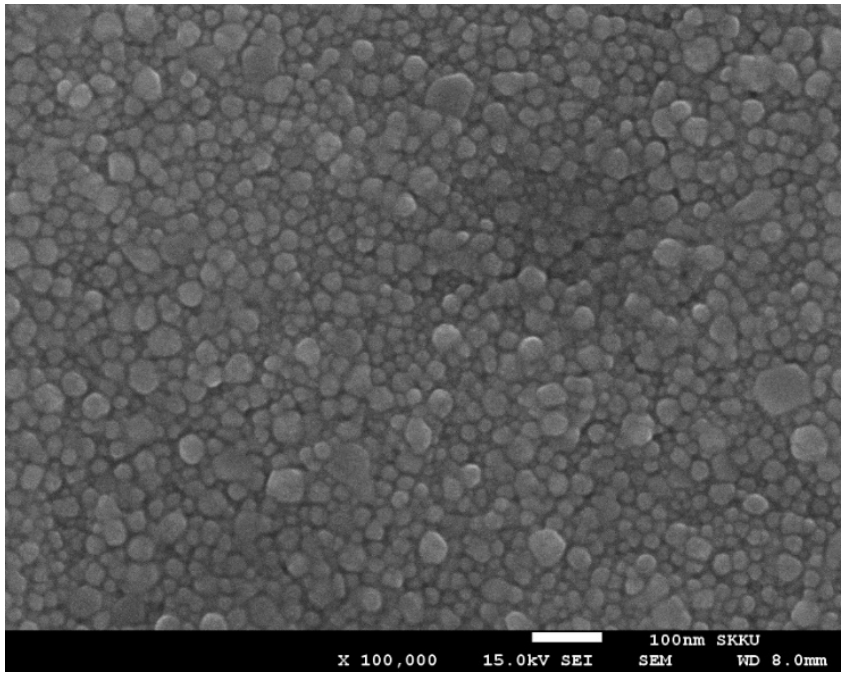

(a)

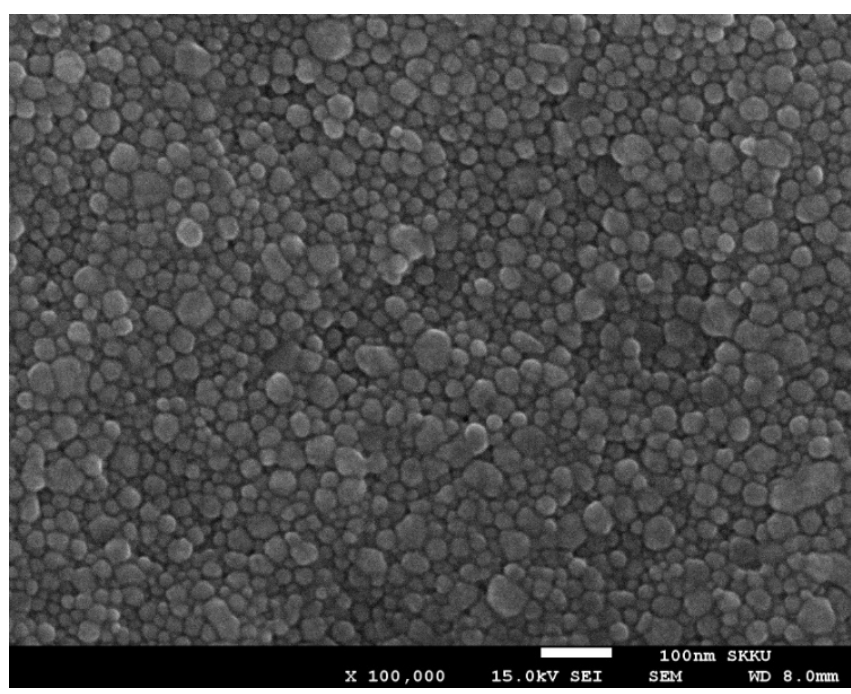

(b)

Figure 7. Cont. 


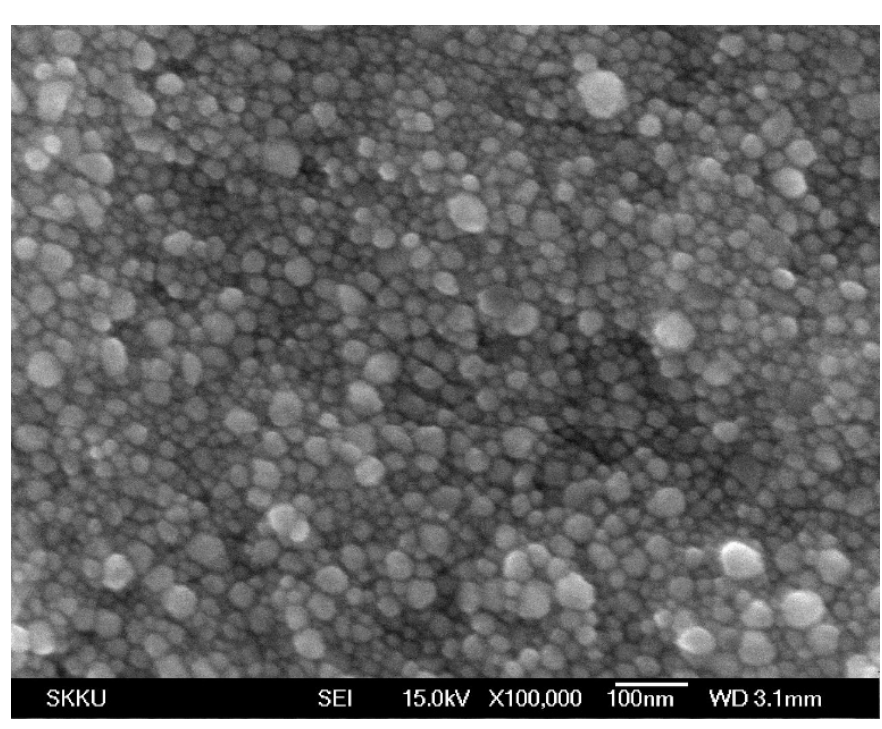

(c)

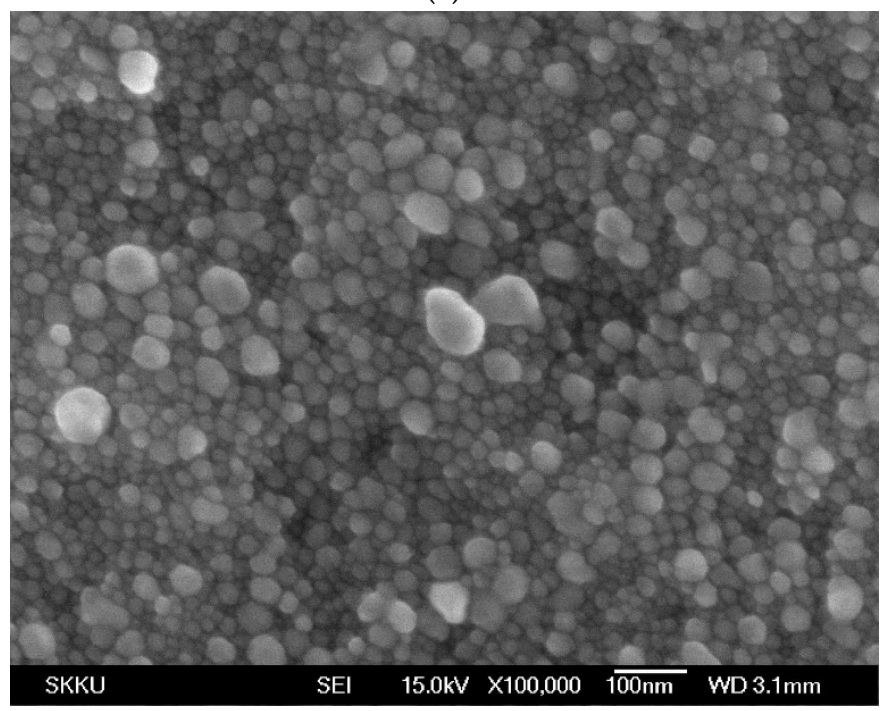

(e)

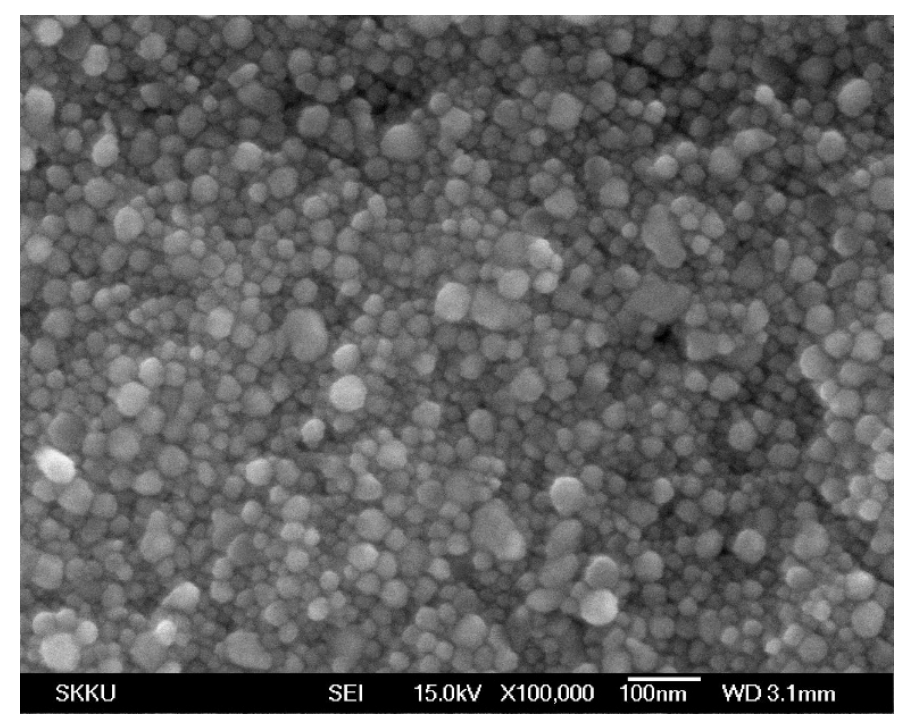

(d)

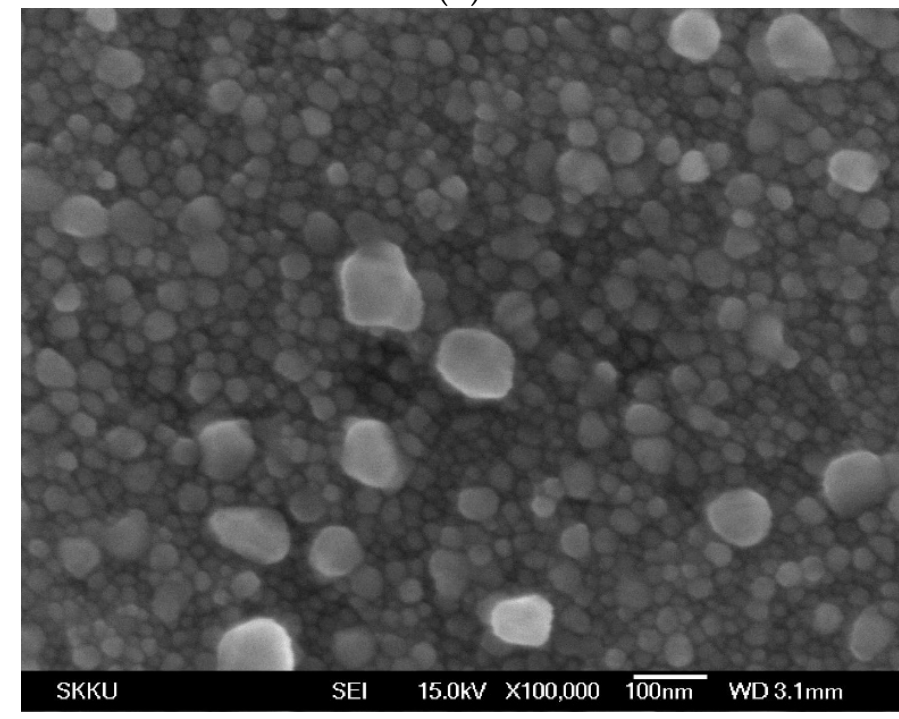

(f)

Figure 7. SEM images showing the surface morphology of thermally treated Ag films: as-deposited (a), annealed at $90{ }^{\circ} \mathrm{C}$ (b), $120^{\circ} \mathrm{C}$ (c), $150{ }^{\circ} \mathrm{C}$ (d) for $10 \mathrm{~min}$. The sample (e,f) were annealed at $150{ }^{\circ} \mathrm{C}$ for 30 and $50 \mathrm{~min}$, respectively.

The crystal structure and the grain size of thermally treated Ag thin films were analyzed by XRD, as shown in Figures 8 and 9. The mean particle diameter in the silver films was calculated from the diffraction peak of Ag (111) plane as following Scherrer Equation (3) [53].

$$
D=\frac{K \lambda}{\beta \cos \theta}
$$

where $\lambda$ is the $X$-ray wavelength $(\mathrm{Cu} \mathrm{K} \alpha, 0.154 \mathrm{~nm})$ in nanometer (nm), $\beta$ is the full width at half-maximum (FWHM) in radians, $\theta$ is the diffraction angle, and $K$ is a constant related to crystallite shape, generally taken as 0.9 . All samples exhibit the several diffraction peaks corresponded to (111), (200), (220), (311), and (222) planes of pure crystalline face-centered cubic (fcc) silver, respectively [54]. The peak of (111) plane was dominant, although Ag (111) and (220) peaks overlapped with XRD peaks associated with PET substrate. The intensity of the peak corresponding to the silver (111) was significantly higher than that of the PET substrate; however, the (220) peaks of silver in the as-deposited and thermally treated silver films also had apparently identical intensities. The peak intensity of (111) plane of Ag films increased slightly after the post-treatment at the different temperatures 
and various durations, suggesting improvement of crystallinity, although the morphology of the particles only had little changes. Table 2 shows the grain size of silver films thermally treated at different conditions. The grains in the films became bigger as the temperature and duration increased, as can also be seen in Figure 7.

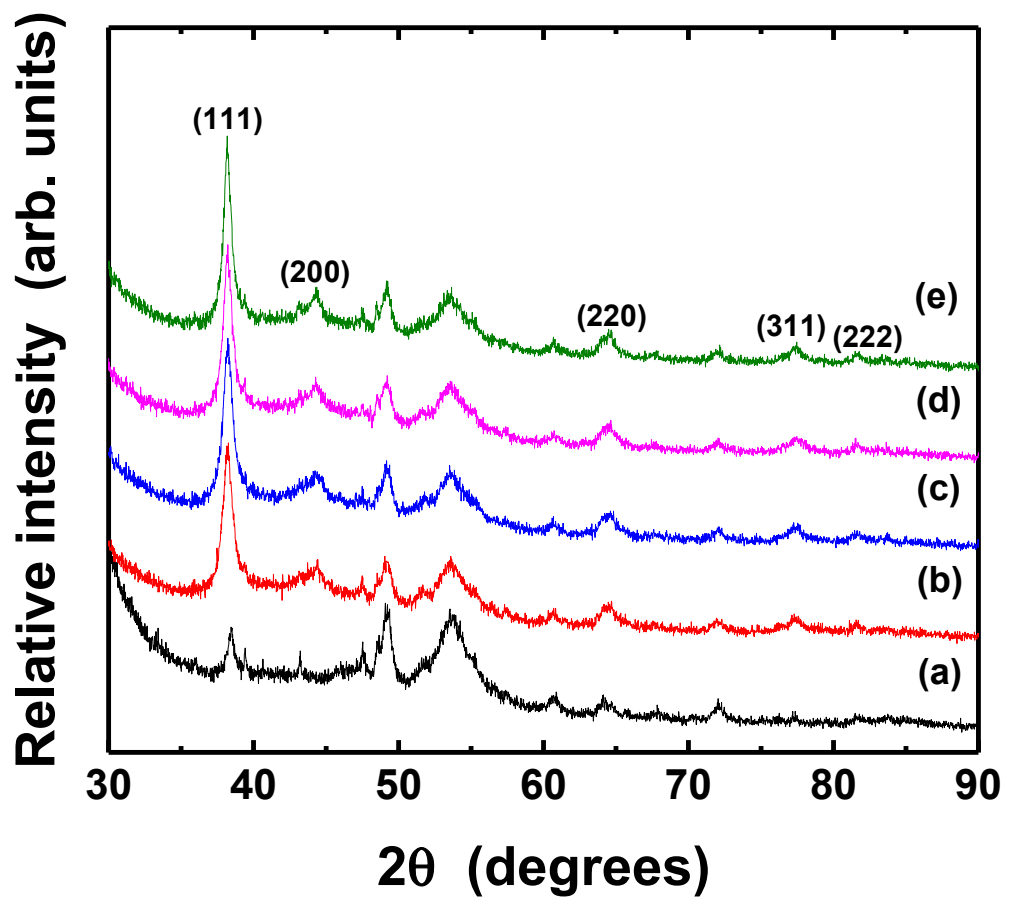

Figure 8. XRD patterns of Ag thin films thermally treated at different temperatures: (a) PET substrate, (b) as-deposited, (c) $90{ }^{\circ} \mathrm{C}$, (d) $120^{\circ} \mathrm{C}$, (e) $150{ }^{\circ} \mathrm{C}$, respectively. The pot-treatment duration was $10 \mathrm{~min}$.

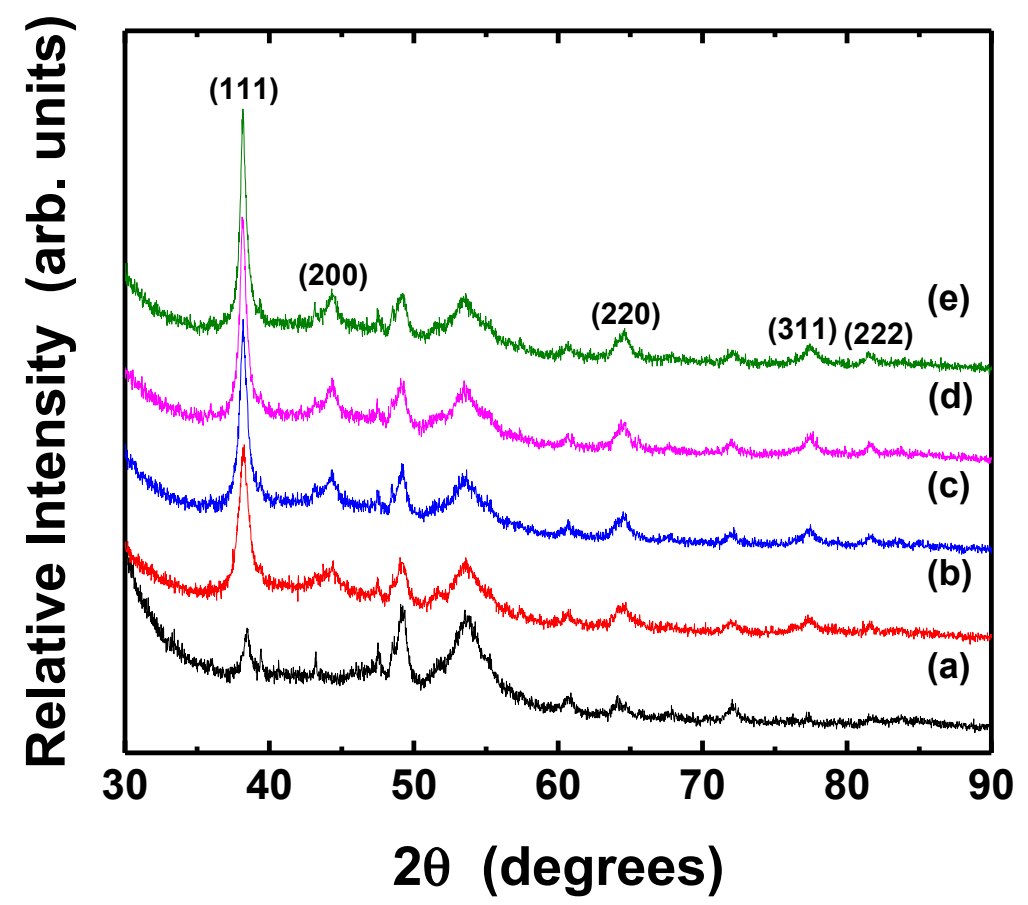

Figure 9. XRD patterns of Ag thin films post-treated for various durations: (a) PET substrate, (b) asdeposited, (c) $10 \mathrm{~min}$, (d) $30 \mathrm{~min}$, (e) $50 \mathrm{~min}$, respectively. All samples were thermally treated at $150{ }^{\circ} \mathrm{C}$. 
Table 2. Grain size of thermally treated Ag thin films under different conditions.

\begin{tabular}{ccccc}
\hline & \multicolumn{4}{c}{ (111) Plan } \\
\cline { 2 - 5 } Post-Treatment Conditions & $\mathbf{2 \theta}$ & $\begin{array}{c}\boldsymbol{d} \\
(\mathbf{D})\end{array}$ & $\begin{array}{c}\text { FWHM } \\
\text { (Degree) }\end{array}$ & $\begin{array}{c}\text { Grain Size } \\
\text { (nm) }\end{array}$ \\
\hline $90^{\circ} \mathrm{C}, 10 \mathrm{~min}$ & 38.232 & 2.3522 & 0.779 & 10.79 \\
\hline $120^{\circ} \mathrm{C}, 10 \mathrm{~min}$ & 38.216 & 2.3531 & 0.738 & 11.39 \\
\hline $150^{\circ} \mathrm{C}, 10 \mathrm{~min}$ & 38.194 & 2.3544 & 0.624 & 13.47 \\
\hline $150{ }^{\circ} \mathrm{C}, 30 \mathrm{~min}$ & 38.17 & 2.3559 & 0.535 & 15.71 \\
\hline $150^{\circ} \mathrm{C}, 50 \mathrm{~min}$ & 38.175 & 2.3556 & 0.497 & 16.91 \\
\hline
\end{tabular}

Figure 10 shows the dependence of the light intensity and irradiation duration of UV-LED modules on the resistivity of Ag films. For a wavelength of $365 \mathrm{~nm}$, the electrical characteristic of Ag films was improved when the silver film was photo-sintered at higher light intensity and for longer irradiation duration. In particular, significant reduction of the resistivity was observed on the samples irradiated with a light intensity of $300 \mathrm{~mW} / \mathrm{cm}^{2}$. The minimum resistivity of $5.44 \times 10^{-6} \Omega \cdot \mathrm{cm}$ (just about three times compared to value of bulk silver) was obtained from the optimum photo-sintering conditions of $300 \mathrm{~mW} / \mathrm{cm}^{2}$ and $50 \mathrm{~min}$. Similar results were obtained for a wavelength of $385 \mathrm{~nm}$, even though the resistivity exhibited larger values in all samples, suggesting the shorter wavelength of UV-LED are more effective for better electrical performance. The minimum resistivity of $5.44 \times 10^{-6} \Omega \cdot \mathrm{cm}$ (sheet resistance of $72.6 \mathrm{~m} \Omega / \mathrm{sq}$ ), comparable value from Ag films photo-sintered with IPL [55], was obtained from the optimum photo-sintering conditions ( $300 \mathrm{~mW} / \mathrm{cm}^{2}$ and $50 \mathrm{~min}$ ). Comparing to values of thermally sintered silver film (Figure 5), the films irradiated with the UV-LED modules appeared to have better electrical conduction, regardless of the wavelength. The significant changes in the electrical resistivity of Ag thin films depending on the sintering conditions are attributed to several reasons. Dziedzic et al. [56] suggested that when the curing temperature got higher, the mass and thickness of the conductive pillars in the carbon/polyesterimide (PEI) composite films decreased, resulting in lower electrical resistance. However, there was no large difference in the thickness of Ag films depending on the curing temperature or the sintering methods (thermal and photo-sintering), although the as-prepared film thickness could not be measured. In addition, no significant changes appeared in the crystal structure (XRD analysis in Figures 8 and 9). Therefore, the improvement of the electrical conductivity after thermaland photo-sintering process is due to greater grain growth as shown in Figure 7.

The temperature changes at different sites of the UV-LED system during irradiation were monitored (Figure 11) in order to investigate the mechanisms governing the process. When the high intensity light was irradiated on the silver nanoparticles film, the film surface and the substrate temperature were saturated to approximately 90 and $130^{\circ} \mathrm{C}$ within 10 min, as shown in Figure 11. The electrical characteristics of photo-sintered film is better than sample thermally annealed at $150^{\circ} \mathrm{C}$, even though the surface temperature during UV-LED irradiation is lower than $150^{\circ} \mathrm{C}$. This might be because of the excited electron resulting from UV-light irradiation. It is possible that the energetic electrons of the silver nanoparticles from the light irradiation remain in the excited state for several picoseconds as Au nanoparticles [57]. Hence, the excited electrons in the nanoparticles might activate reactant molecules, ethylene glycol, adsorbed on the Ag nanoparticles, and lead to more chemical reactions under lower temperature than its dehydration temperature [51].

The surface morphologies of UV-LED sintered silver films were different from those of thermally treated samples, as shown in Figure 12. There is little change on the surface when the films were irradiated for a short time (i.e., $10 \mathrm{~min}$ ), regardless of the light intensity. As the irradiation duration further increased, coarsening of intergranular silver nanoparticles occurred and the grains got larger. 


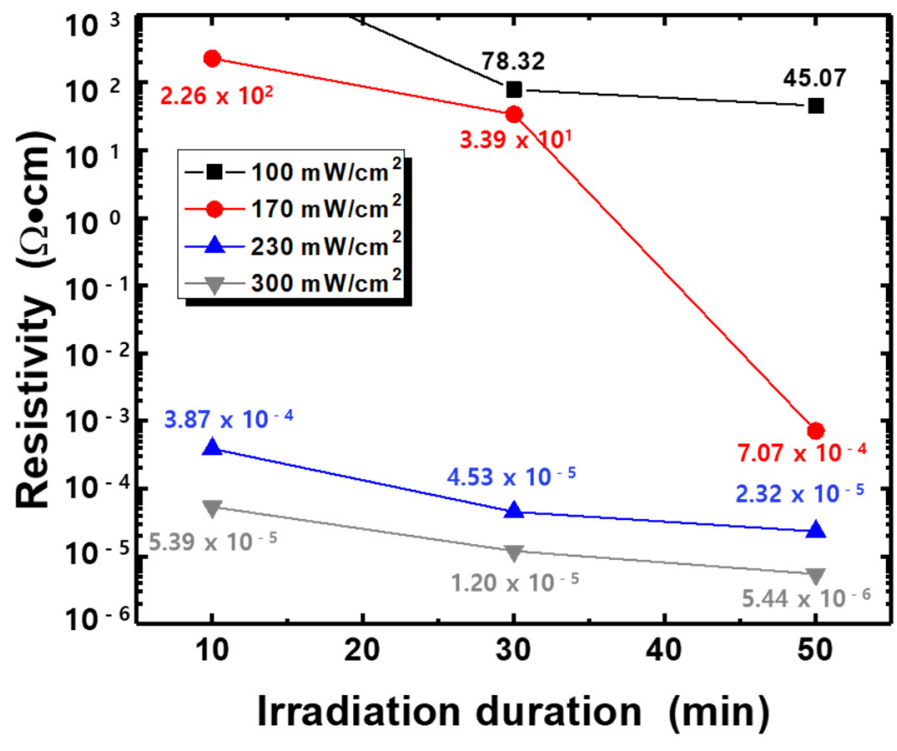

(a)

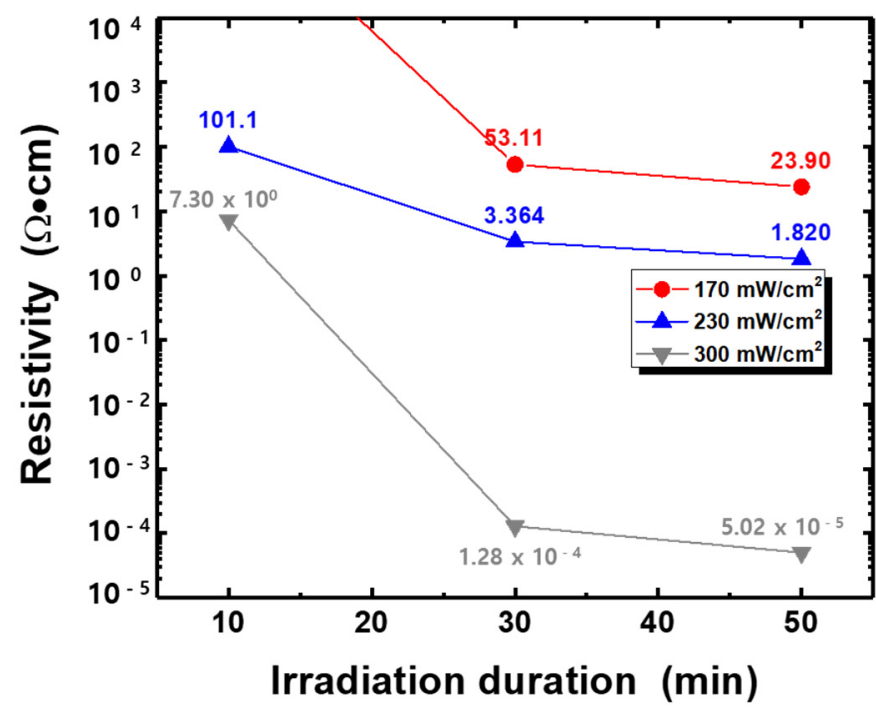

(b)

Figure 10. Dependence of the light intensity and irradiation duration of UV-LED module on the electrical resistivity of Ag films: (a) $365 \mathrm{~nm}$, (b) $385 \mathrm{~nm}$.

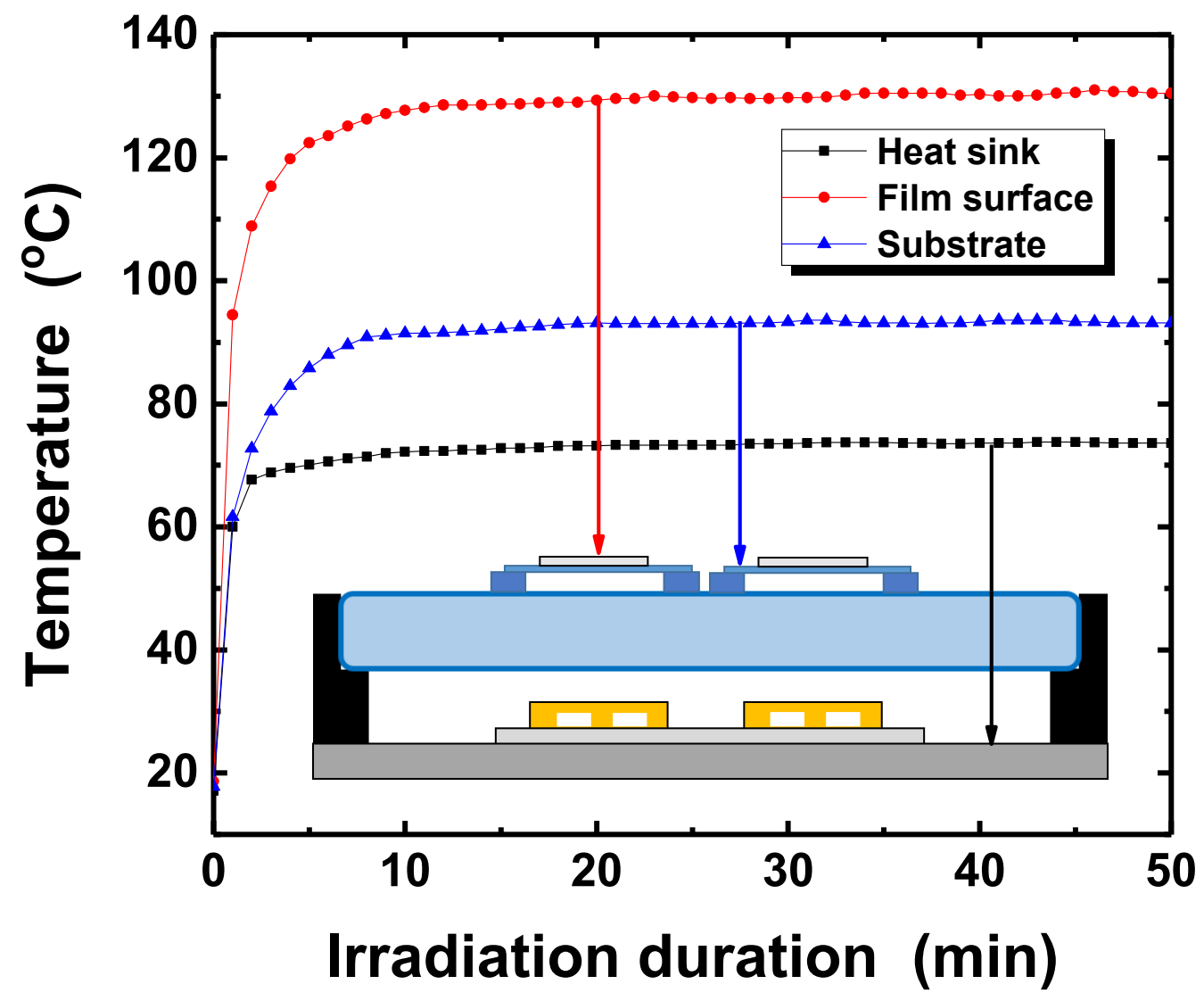

Figure 11. Temperature profiles of the silver film surface, the substrate, and the heat sink as a function of the irradiation duration. The light intensity of UV-LED module with the wavelength of $365 \mathrm{~nm}$ was $300 \mathrm{~mW} / \mathrm{cm}^{2}$. 


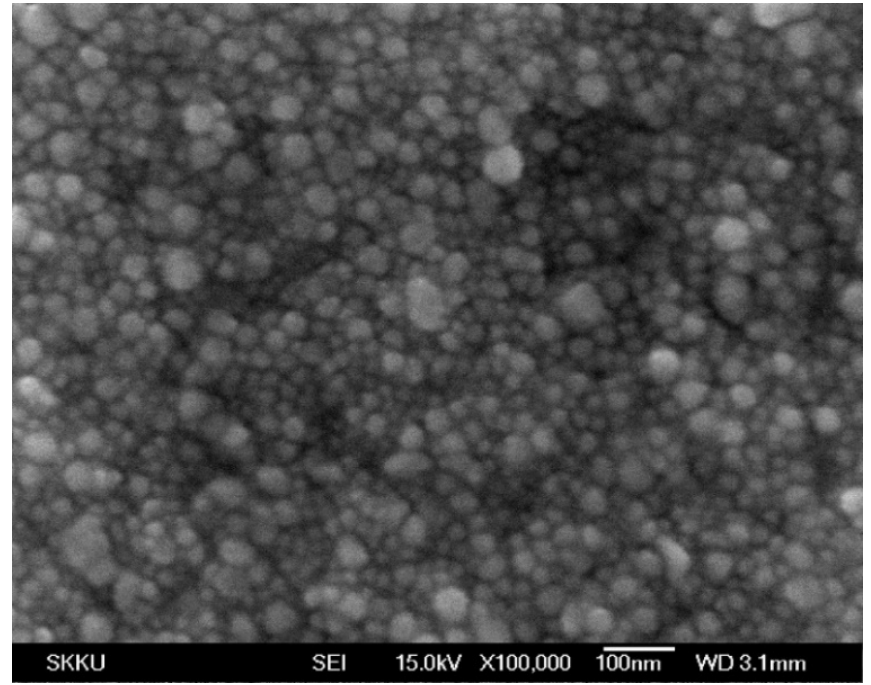

(a)

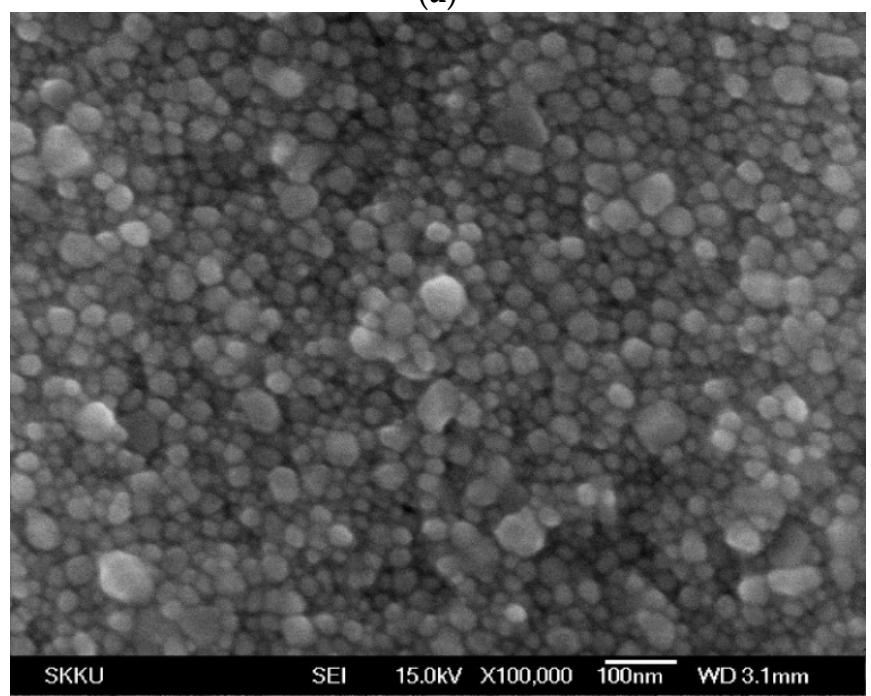

(c)

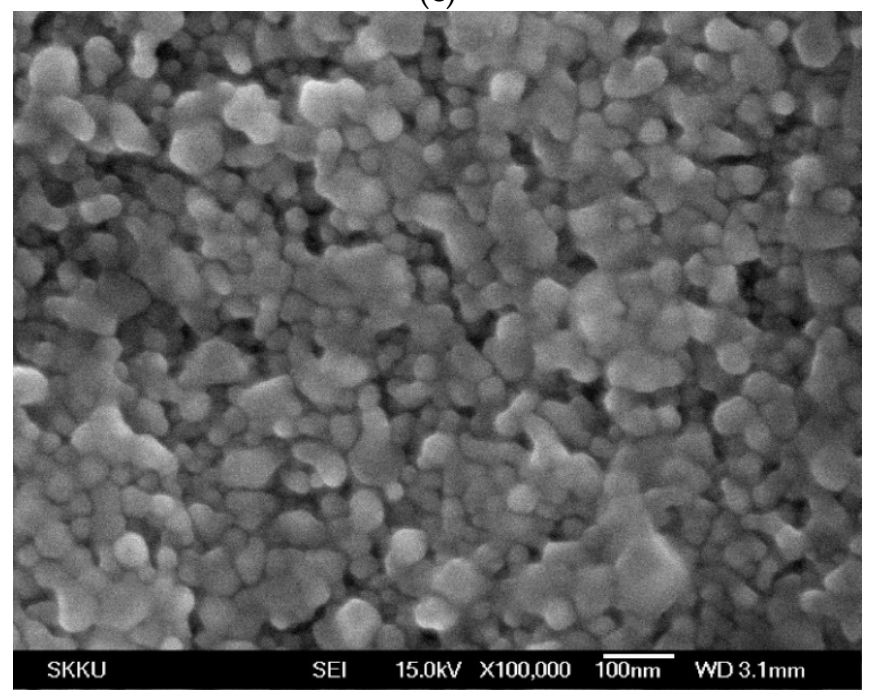

(e)

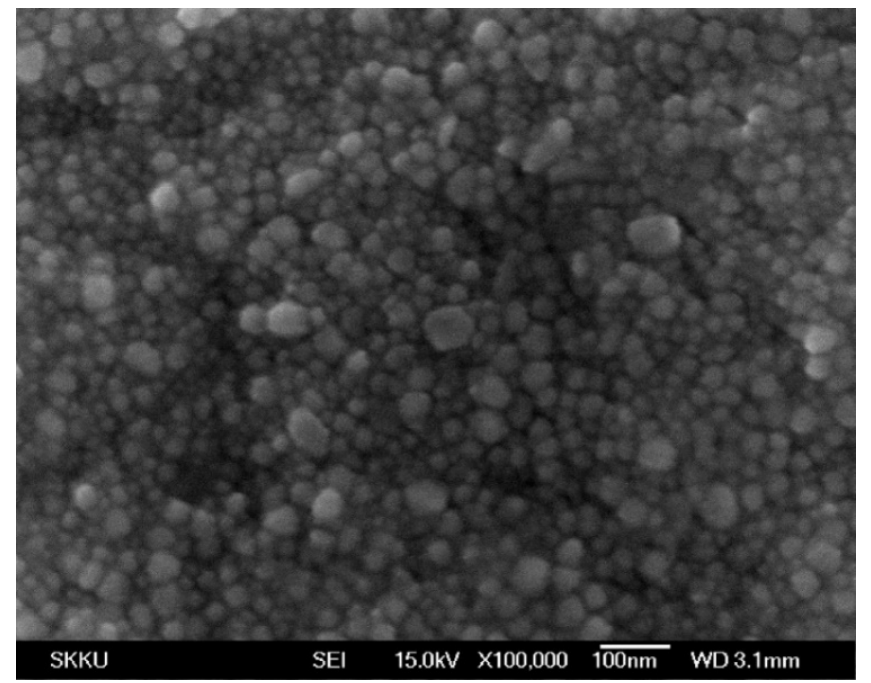

(b)

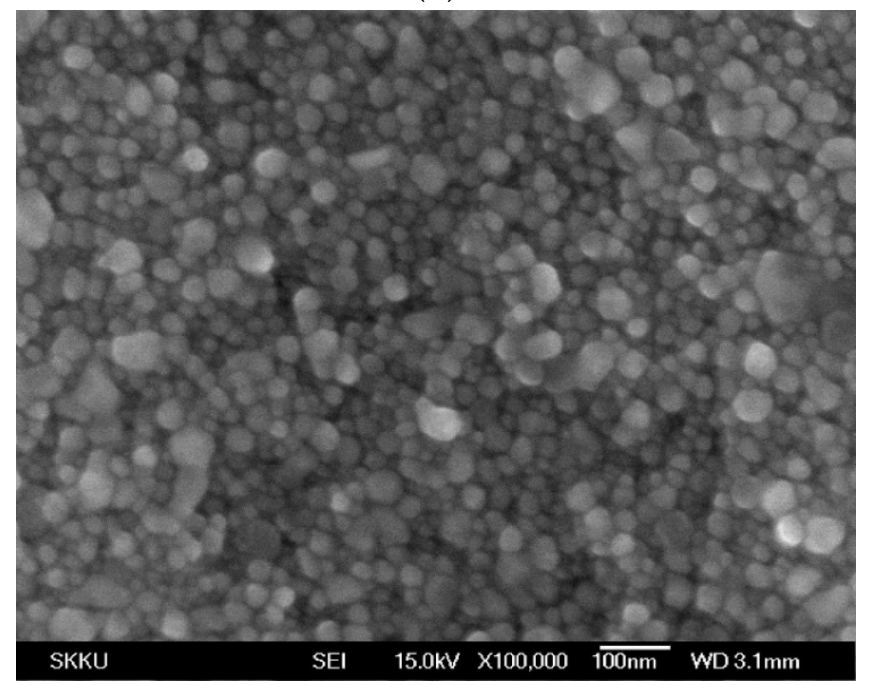

(d)

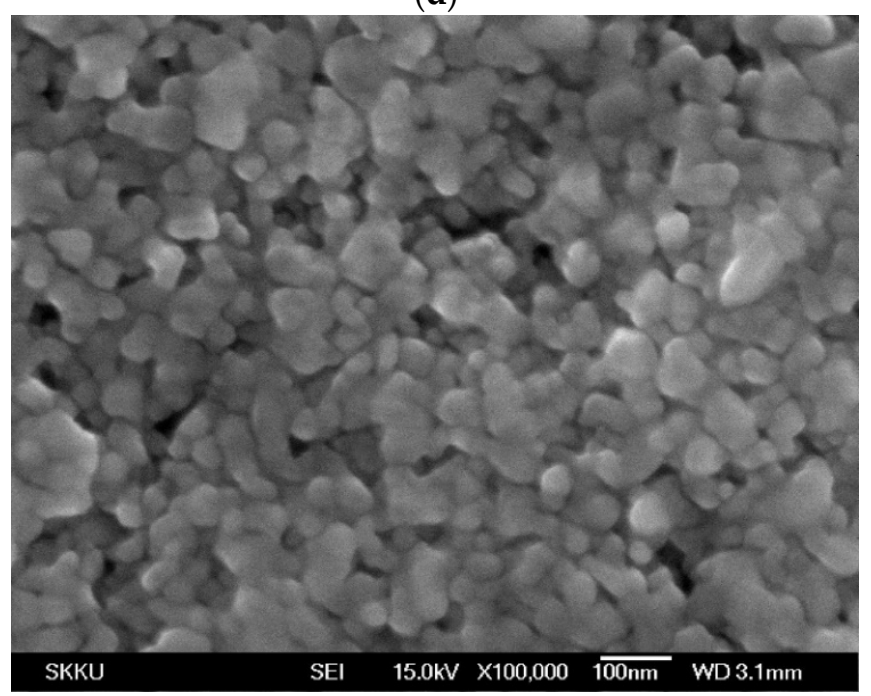

(f)

Figure 12. Surface morphologies of photo-sintered Ag films under various conditions: $100 \mathrm{~mW} / \mathrm{cm}^{2}(\mathbf{a}), 170 \mathrm{~mW} / \mathrm{cm}^{2}(\mathbf{b})$, $230 \mathrm{~mW} / \mathrm{cm}^{2}$ (c), $300 \mathrm{~mW} / \mathrm{cm}^{2}$ (d) for $10 \mathrm{~min}$, respectively. The sample (e,f) were photo-sintered at $300 \mathrm{~mW} / \mathrm{cm}^{2}$ for $30 \mathrm{~min}$ and $50 \mathrm{~min}$. The wavelength of UV-LED module was $365 \mathrm{~nm}$. 
Figures 13 and 14 show the XRD patterns of Ag thin films photo-sintered under different conditions. The (1 111 ) peak of fcc silver phase became sharper after UV-LED irradiation, indicating that the crystallinity of the film improved, regardless of photosintering conditions. In particular, the increase of peak intensity was prominent when the film was irradiated for $50 \mathrm{~min}$ (Figure 14e). The mean grain diameter of photo-sintered silver films was calculated from the Ag (111) plane peak using Scherrer equation (Table 3). The grains in the Ag films enlarged as the light intensity and irradiation duration increased. Compared to thermally sintering film, the grain size of the film photo-sintered at high power and longer irradiation (i.e., $300 \mathrm{~mW} / \mathrm{cm}^{2}, 30$ and $50 \mathrm{~min}$ ) was larger.

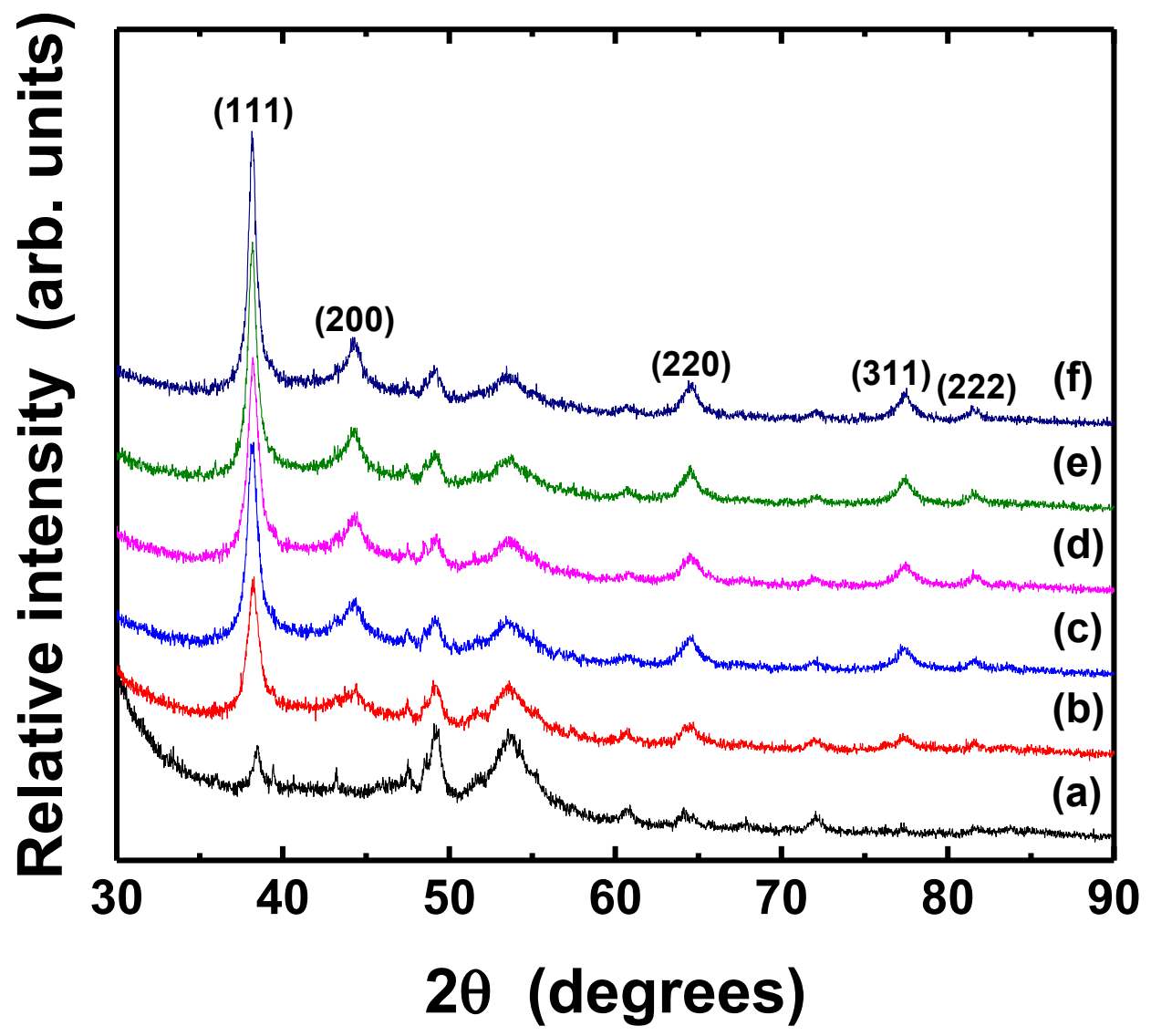

Figure 13. XRD patterns of Ag thin films photo-sintered at different light intensities: PET substrate (a), as-deposited film (b), $100 \mathrm{~mW} / \mathrm{cm}^{2}$ (c), $170 \mathrm{~mW} / \mathrm{cm}^{2}$ (d), $230 \mathrm{~mW} / \mathrm{cm}^{2}$ (e), and $300 \mathrm{~mW} / \mathrm{cm}^{2}$ (f), respectively. The wavelength of UV-LED module was $365 \mathrm{~nm}$, and all samples were photo-sintered for $10 \mathrm{~min}$.

Table 3. Grain size of Ag thin films photo-sintered at various light intensities and for different irradiation durations. The wavelength of UV-LED module was $365 \mathrm{~nm}$.

\begin{tabular}{ccccc}
\hline & \multicolumn{4}{c}{ (111) Plan } \\
\cline { 2 - 5 } Post-Treatment Conditions & $\begin{array}{c}\mathbf{2 \theta} \\
\text { (Degree) }\end{array}$ & $\begin{array}{c}\boldsymbol{d} \\
(\mathbf{A})\end{array}$ & $\begin{array}{c}\text { FWHM } \\
\text { (Degree) }\end{array}$ & $\begin{array}{c}\text { Grain Size } \\
\text { (nm) }\end{array}$ \\
\hline $100 \mathrm{~mW} / \mathrm{cm}^{2}, 10 \mathrm{~min}$ & 38.167 & 2.3560 & 0.742 & 11.33 \\
\hline $170 \mathrm{~mW} / \mathrm{cm}^{2}, 10 \mathrm{~min}$ & 38.211 & 2.3535 & 0.736 & 11.42 \\
\hline $230 \mathrm{~mW} / \mathrm{cm}^{2}, 10 \mathrm{~min}$ & 38.157 & 2.3567 & 0.606 & 13.87 \\
\hline $300 \mathrm{~mW} / \mathrm{cm}^{2}, 10 \mathrm{~min}$ & 38.167 & 2.3560 & 0.542 & 15.51 \\
\hline $300 \mathrm{~mW} / \mathrm{cm}^{2}, 30 \mathrm{~min}$ & 38.181 & 2.3552 & 0.456 & 18.44 \\
\hline $300 \mathrm{~mW} / \mathrm{cm}^{2}, 50 \mathrm{~min}$ & 38.198 & 2.3542 & 0.393 & 21.39 \\
\hline
\end{tabular}




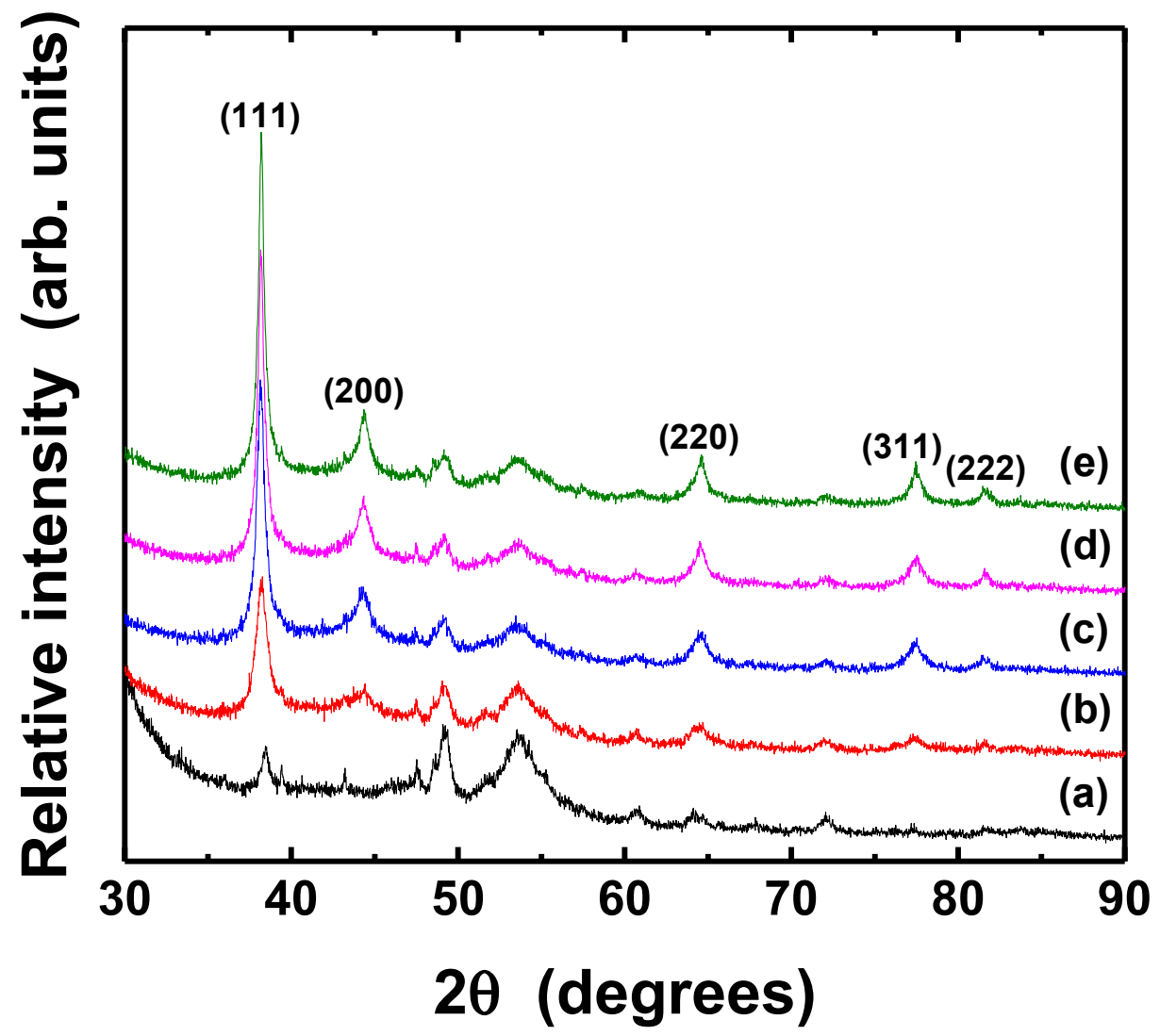

Figure 14. XRD patterns of Ag films irradiated for various durations: PET substrate (a), as-deposited (b), $10 \mathrm{~min}(\mathbf{c}), 30 \mathrm{~min}(\mathbf{d})$, and $50 \mathrm{~min}(\mathbf{e})$, respectively. The wavelength and the light intensity of UV-LED module were $365 \mathrm{~nm}$ and $300 \mathrm{~mW} / \mathrm{cm}^{2}$, respectively.

\section{Conclusions}

This work studied the UV-LED light sintering effects on the electrical and structural properties of silver thin films inkjet-printed on the PET substrate. For comparison, the films were also thermally sintered at different temperatures and for various durations. The TG/DTA analysis revealed that minimum temperature of $160.6{ }^{\circ} \mathrm{C}$ was required for post-annealing of $\mathrm{Ag}$ films. The post-treatment temperature showing good electrical performance was $150^{\circ} \mathrm{C}$ and the sheet resistance reduced significantly with the thermal sintering time. Using optimized irradiation conditions like a light intensity of $300 \mathrm{~mW} / \mathrm{cm}^{2}$ and an irradiation duration of $50 \mathrm{~min}$, the minimum resistivity of $5.44 \times 10^{-6} \Omega \cdot \mathrm{cm}$ (much smaller value compared to thermally sintered $\mathrm{Ag}$ film) could be obtained even though the film was post-treated in air atmosphere, instead of vacuum. In addition, the UV-LED with a shorter wavelength $(365 \mathrm{~nm})$ was more adequate for better electrical performance. The new photo-sintering system with the high-power UV-LED module can be applicable to large area applications for various metals and semiconductor to achieve good electrical properties.

Author Contributions: Conceptualization, M.K. and J.L.; methodology, M.K.; data curation, M.K. and H.J.; writing-original draft preparation, M.K. and J.L.; writing-review and editing, H.J. and J.L.; supervision, J.L. All authors have read and agreed to the published version of the manuscript.

Funding: This work was supported by the Korean Institute of Energy Technology Evaluation and Planning (KETEP) and the Ministry of Trade, Industry \& Energy (MOTIE) of the Republic of Korea. (No. 20203030010200) Also, this work was supported by the National Research Foundation of Korea (NRF) grant funded by the Korea government (MSIT) (No. 2019R1F1A1061615).

Data Availability Statement: The data that support the findings of this study are available upon reasonable request.

Conflicts of Interest: The authors declare no conflict of interest. 


\section{References}

1. Wiklund, J.; Karakoç, A.; Palko, T.; Yiğitler, H.; Ruttik, K.; Jäntti, R.; Paltakari, J. A Review on Printed Electronics: Fabrication Methods, Inks, Substrates, Applications and Environmental Impacts. J. Manuf. Mater. Process. 2021, 5, 89. [CrossRef]

2. Kwon, K.-S.; Rahman, K.; Phung, T.H.; Hoath, S.; Jeong, S.; Kim, J.S. Review of digital printing technologies for electronic materials. Flex. Print. Electron. 2020, 5, 043003. [CrossRef]

3. Raut, N.C.; Al-Shamery, K. Inkjet printing metals on flexible materials for plastic and paper electronics. J. Mater. Chem. C 2018, 6, 1618-1641. [CrossRef]

4. Luo, Q. 5-Nanoparticles inks. In Solution Processed Metal Oxide Thin Films for Electronic Applications; Cui, Z., Korotcenkov, G., Eds.; Elsevier: Amsterdam, The Netherlands, 2020; pp. 63-82. [CrossRef]

5. Tiyyagura, H.; Majerič, P.; Bračič, M.; Anžel, I.; Rudolf, R. Gold Inks for Inkjet Printing on Photo Paper: Complementary Characterisation. Nanomaterials 2021, 11, 599. [CrossRef] [PubMed]

6. Liew, Q.; Rashid, N.A.; Lee, H.; Hawari, H.; Khir, M.M. Inkjet-Printed Flexible Temperature Sensor using Hybrid Reduced Graphene Oxide-Silver Nanoparticles(rGO/AgNPs) Conductive Ink and Silver Nanoparticles Ink. J. Phys. Conf. Ser. 2021, 1878, 012059. [CrossRef]

7. Majee, S.; Karlsson, M.C.F.; Sawatdee, A.; Mulla, M.Y.; Alvi, N.U.H.; Beni, V.; Nilsson, D. Low temperature chemical sintering of inkjet-printed Zn nanoparticles for highly conductive flexible electronic components. NPJ Flex. Electron. 2021, 5, 1-8. [CrossRef]

8. Huang, Y.; Xie, X.; Li, M.; Xu, M.; Long, J. Copper circuits fabricated on flexible polymer substrates by a high repetition rate femtosecond laser-induced selective local reduction of copper oxide nanoparticles. Opt. Express 2021, 29, 4453-4463. [CrossRef]

9. Huang, Q.; Zhu, Y. Printing Conductive Nanomaterials for Flexible and Stretchable Electronics: A Review of Materials, Processes, and Applications. Adv. Mater. Technol. 2019, 4, 1800546. [CrossRef]

10. Khan, Y.; Thielens, A.; Muin, S.; Ting, J.; Baumbauer, C.; Arias, A.C. A New Frontier of Printed Electronics: Flexible Hybrid Electronics. Adv. Mater. 2019, 32, e1905279. [CrossRef]

11. Wu, W. Inorganic nanomaterials for printed electronics: A review. Nanoscale 2017, 9, 7342-7372. [CrossRef] [PubMed]

12. Baumbauer, C.L.; Anderson, M.G.; Ting, J.; Sreekumar, A.; Rabaey, J.M.; Arias, A.C.; Thielens, A. Printed, flexible, compact UHF-RFID sensor tags enabled by hybrid electronics. Sci. Rep. 2020, 10, 16543. [CrossRef] [PubMed]

13. Yan, K.; Li, J.; Pan, L.; Shi, Y. Inkjet printing for flexible and wearable electronics. APL Mater. 2020, 8, 120705. [CrossRef]

14. Noginov, M.; Zhu, G.; Bahoura, M.; Adegoke, J.; Small, C.; Ritzo, B.; Drachev, V.; Shalaev, V. The effect of gain and absorption on surface plasmons in metal nanoparticles. Appl. Phys. A 2006, 86, 455-460. [CrossRef]

15. Bohren, C.F. How can a particle absorb more than the light incident on it? Am. J. Phys. 1983, 51, 323-327. [CrossRef]

16. Grouchko, M.; Kamyshny, A.; Mihailescu, C.F.; Anghel, D.F.; Magdassi, S. Conductive Inks with a "Built-In" Mechanism That Enables Sintering at Room Temperature. ACS Nano 2011, 5, 3354-3359. [CrossRef]

17. Huang, Q.; Shen, W.; Xu, Q.; Tan, R.; Song, W. Properties of polyacrylic acid-coated silver nanoparticle ink for inkjet printing conductive tracks on paper with high conductivity. Mater. Chem. Phys. 2014, 147, 550-556. [CrossRef]

18. Allen, M.L. Nanoparticle Sintering Methods and Applications for Printed Electronics. Ph.D. Thesis, Aalto University, Helsinki, Finland, 2011. ISBN 978-952-60-4277-0.

19. Allen, M.L.; Aronniemi, M.; Mattila, T.; Alastalo, A.; Ojanperä, K.; Suhonen, M.; Seppä, H. Electrical sintering of nanoparticle structures. Nanotechnology 2008, 19, 175201. [CrossRef]

20. Xie, G.; Ohashi, O.; Yamaguchi, N.; Wang, A. Effect of surface oxide films on the properties of pulse electric-current sintered metal powders. Met. Mater. Trans. A 2003, 34, 2655-2661. [CrossRef]

21. Gu, W.; Yuan, W.; Zhong, T.; Wu, X.; Zhou, C.; Lin, J.; Cui, Z. Fast near infrared sintering of silver nanoparticle ink and applications for flexible hybrid circuits. RSC Adv. 2018, 8, 30215-30222. [CrossRef]

22. Sowade, E.; Kang, H.; Mitra, K.Y.; Weiß, O.J.; Weber, J.; Baumann, R.R. Roll-to-roll infrared (IR) drying and sintering of an inkjet-printed silver nanoparticle ink within 1 second. J. Mater. Chem. C 2015, 3, 11815-11826. [CrossRef]

23. Denneulin, A.; Blayo, A.; Neuman, C.; Bras, J. Infra-red assisted sintering of inkjet printed silver tracks on paper substrates. J. Nanoparticle Res. 2011, 13, 3815-3823. [CrossRef]

24. Cherrington, M.; Claypole, T.C.; Deganello, D.; Mabbett, I.; Watson, T.; Worsley, D. Ultrafast near-infrared sintering of a slot-die coated nano-silver conducting ink. J. Mater. Chem. 2011, 21, 7562-7564. [CrossRef]

25. Balliu, E.; Andersson, H.; Engholm, M.; Öhlund, T.; Nilsson, H.-E.; Olin, H. Selective laser sintering of inkjet-printed silver nanoparticle inks on paper substrates to achieve highly conductive patterns. Sci. Rep. 2018, 8, 10408. [CrossRef]

26. Yeo, J.; Kim, G.; Hong, S.; Kim, M.S.; Kim, D.; Lee, J.; Lee, H.B.; Kwon, J.; Suh, Y.D.; Kang, H.W.; et al. Flexible supercapacitor fabrication by room temperature rapid laser processing of roll-to-roll printed metal nanoparticle ink for wearable electronics application. J. Power Sources 2013, 246, 562-568. [CrossRef]

27. Hong, S.; Yeo, J.; Kim, G.; Kim, D.; Lee, H.; Kwon, J.; Lee, H.; Lee, P.; Ko, S.H. Nonvacuum, Maskless Fabrication of a Flexible Metal Grid Transparent Conductor by Low-Temperature Selective Laser Sintering of Nanoparticle Ink. ACS Nano 2013, 7, 5024-5031. [CrossRef]

28. Perelaer, J.; Abbel, R.; Wünscher, S.; Jani, R.; Van Lammeren, T.; Schubert, U. Roll-to-Roll Compatible Sintering of Inkjet Printed Features by Photonic and Microwave Exposure: From Non-Conductive Ink to $40 \%$ Bulk Silver Conductivity in Less Than 15 Seconds. Adv. Mater. 2012, 24, 2620-2625. [CrossRef] 
29. Perelaer, J.; Klokkenburg, M.; Hendriks, C.E.; Schubert, U.S. Microwave Flash Sintering of Inkjet-Printed Silver Tracks on Polymer Substrates. Adv. Mater. 2009, 21, 4830-4834. [CrossRef] [PubMed]

30. Perelaer, J.J.; De Gans, B.B.-J.; Schubert, U.U. Ink-jet Printing and Microwave Sintering of Conductive Silver Tracks. Adv. Mater. 2006, 18, 2101-2104. [CrossRef]

31. Wünscher, S.; Stumpf, S.; Perelaer, J.; Schubert, U.S. Towards single-pass plasma sintering: Temperature influence of atmospheric pressure plasma sintering of silver nanoparticle ink. J. Mater. Chem. C 2013, 2, 1642-1649. [CrossRef]

32. Ma, S.; Bromberg, V.; Liu, L.; Egitto, F.D.; Chiarot, P.R.; Singler, T.J. Low temperature plasma sintering of silver nanoparticles. Appl. Surf. Sci. 2014, 293, 207-215. [CrossRef]

33. Wünscher, S.; Stumpf, S.; Teichler, A.; Pabst, O.; Perelaer, J.; Beckert, E.; Schubert, U.S. Localized atmospheric plasma sintering of inkjet printed silver nanoparticles. J. Mater. Chem. 2012, 22, 24569-24576. [CrossRef]

34. Reinhold, I.; Hendriks, C.E.; Eckardt, R.; Kranenburg, J.M.; Perelaer, J.; Baumann, R.R.; Schubert, U.S. Argon plasma sintering of inkjet printed silver tracks on polymer substrates. J. Mater. Chem. 2009, 19, 3384-3388. [CrossRef]

35. Sarkar, S.K.; Gupta, H.; Gupta, D. Flash Light Sintering of Silver Nanoink for Inkjet-Printed Thin-Film Transistor on Flexible Substrate. IEEE Trans. Nanotechnol. 2017, 16, 375-382. [CrossRef]

36. Chung, W.-H.; Hwang, H.-J.; Lee, S.-H.; Kim, H.-S. In situmonitoring of a flash light sintering process using silver nano-ink for producing flexible electronics. Nanotechnology 2012, 24, 035202. [CrossRef]

37. Abbel, R.; van Lammeren, T.; Hendriks, R.; Ploegmakers, J.; Rubingh, E.J.; Meinders, E.R.; Groen, P. Photonic flash sintering of silver nanoparticle inks: A fast and convenient method for the preparation of highly conductive structures on foil. MRS Commun. 2012, 2, 145-150. [CrossRef]

38. Kang, J.S.; Ryu, J.; Kim, H.S.; Hahn, H.T. Sintering of Inkjet-Printed Silver Nanoparticles at Room Temperature Using Intense Pulsed Light. J. Electron. Mater. 2011, 40, 2268-2277. [CrossRef]

39. Lee, D.J.; Park, S.H.; Jang, S.; Kim, H.-S.; Oh, J.H.; Song, Y.W. Pulsed light sintering characteristics of inkjet-printed nanosilver films on a polymer substrate. J. Micromechan. Microeng. 2011, 21, 125023. [CrossRef]

40. West, J.; Carter, M.; Smith, S.; Sears, J. Photonic Curing of Silver Nanoparticle Based Inks. In Proceedings of the Nano Science and Technology Institute (NSTI) Nanotechnology Conference, Anahaim, CA, USA, 21-24 June 2010; pp. $210-213$.

41. Yung, K.; Gu, X.; Lee, C.; Choy, H. Ink-jet printing and camera flash sintering of silver tracks on different substrates. J. Mater. Process. Technol. 2010, 210, 2268-2272. [CrossRef]

42. Schroder, K.A.; McCool, S.C.; Furlan, W.F. Broadcast Photonic Curing of Metallic Nanoparticle Films. In Proceedings of the Nano Science and Technology Institute (NSTI) Nanotechnology Conference, Boston, MA, USA, 7-11 May 2006; pp. $198-201$.

43. Jang, Y.-R.; Ryu, C.-H.; Hwang, Y.-T.; Kim, H.-S. Optimization of Intense Pulsed Light Sintering Considering Dimensions of Printed Cu Nano/Micro-paste Patterns for Printed Electronics. Int. J. Precis. Eng. Manuf. Technol. 2020, 8, 471-485. [CrossRef]

44. Jang, Y.-R.; Jeong, R.; Kim, H.-S.; Park, S.S. Fabrication of solderable intense pulsed light sintered hybrid copper for flexible conductive electrodes. Sci. Rep. 2021, 11, 14551. [CrossRef]

45. Hwang, H.-J.; Devaraj, H.; Yang, C.; Gao, Z.; Chang, C.-H.; Lee, H.; Malhotra, R. Rapid Pulsed Light Sintering of Silver Nanowires on Woven Polyester for personal thermal management with enhanced performance, durability and cost-effectiveness. Sci. Rep. 2018, 8, 17159. [CrossRef] [PubMed]

46. Chung, W.-H.; Jang, Y.-R.; Hwang, Y.-T.; Kim, S.-H.; Kim, H.-S. The surface plasmonic welding of silver nanowiresviaintense pulsed light irradiation combined with NIR for flexible transparent conductive films. Nanoscale 2020, 12, 17725-17737. [CrossRef]

47. Noh, Y.; Jeong, H.; Lee, D. Enhanced ultraviolet photodetector using zinc oxide nanowires with intense pulsed light post-treatment. J. Alloys Compd. 2021, 871, 159537. [CrossRef]

48. Park, S.-H.; Kim, H.-S. Flash light sintering of nickel nanoparticles for printed electronics. Thin Solid Films 2014, 550, 575-581. [CrossRef]

49. Skoog, D.A.; Holler, F.J.; Nieman, T.A. Principles of Instrumental Analysis, 5th ed.; Brooks/Cole: Belmont, CA, USA, 1998; pp. 336-341.

50. Shatokha, V. Sintering-Methods and Products; InTech: Rijeka, Croatia, 2012; p. 177. [CrossRef]

51. Sarina, S.; Waclawik, E.R.; Zhu, H. Photocatalysis on supported gold and silver nanoparticles under ultraviolet and visible light irradiation. Green Chem. 2013, 15, 1814-1833. [CrossRef]

52. Fievet, F.; Lagier, J.; Blin, B.; Beaudoin, B.; Figlarz, M. Homogeneous and heterogeneous nucleations in the polyol process for the preparation of micron and submicron size metal particles. Solid State Ionics 1989, 32-33, 198-205. [CrossRef]

53. Cullity, B.D.; Stock, S.R. Elements of X-Ray Diffraction, 3rd ed.; Pearson Education Limited: Harlow, UK, 2014 ; pp. 92-96.

54. Jiang, H.; Tang, C.; Wang, Y.; Mao, L.; Sun, Q.; Zhang, L.; Song, H.; Huang, F.; Zuo, C. Low content and low-temperature cured silver nanoparticles/silver ion composite ink for flexible electronic applications with robust mechanical performance. Appl. Surf. Sci. 2021, 564, 150447. [CrossRef]

55. Zikulnig, J.; Roshanghias, A.; Rauter, L.; Hirschl, C. Evaluation of the Sheet Resistance of Inkjet-Printed Ag-Layers on Flexible, Uncoated Paper Substrates Using Van-der-Pauw's Method. Sensors 2020, 20, 2398. [CrossRef] [PubMed]

56. Dziedzic, A.; Magiera, A.; Winśiewski, R. Hydrostatic high pressure studies of polymer thick-film resistors. Microelectron. Reliab. 1998, 38, 1893-1898. [CrossRef]

57. Haruta, M.; Daté, M. Advances in the catalysis of Au nanoparticles. Appl. Catal. A Gen. 2001, 222, 427-437. [CrossRef] 